\title{
The Importance of Physical Activity in the Protection of the Mental Health of Students of Faculty of Sport Sciences
}

\author{
Halil Tanır ${ }^{1}$, Murat Özmaden ${ }^{1}$ \\ ${ }^{1}$ Adnan Menderes University, Faculty of Sports Sciences, Aydın, Turkey. \\ Correspondence: Halil Tanır, Faculty of Sports Sciences, Adnan Menderes University, Aydın, Turkey.
}

Received: July 17, 2018

Accepted: August 3, 2018

Online Published: August 15, 2018

doi:10.11114/jets.v6i10.3539

URL: https://doi.org/10.11114/jets.v6i10.3539

\begin{abstract}
The purpose of the present research is determining the psychological symptoms observed among the students of the Faculty of Sports Sciences and to define the effects of physical activity on the mental health of the students. The sample of the research consists of 222 volunteer students ( $\mathrm{n}=75$ female and $n=147$ male) who study at Adnan Menderes University Faculty of Sports Sciences in 2017-2018 Academic Year. International Physical Activity Questionnaire (IPAQ) was used to define the physical activity levels of students and Symptom Distress Check List (SCL-90-R) was used to define the psychological symptoms of the students. SPSS 22.0 package program was used for the statistical analysis of the data collected for the present research. According to the findings of the statistical analyses, the most frequent psychological symptoms observed among students respectively were obsessive-compulsive symptoms (70.3\%, $\mathrm{n}=156)$, paranoid thoughts $(63.1 \%, \mathrm{n}=140)$, interpersonal sensitivity $(51.8 \%, \mathrm{n}=115)$ and anger hostility $(51.4 \%, \mathrm{n}=114)$. It was also found that there was a significant negative correlation between the physical activity levels of the students and general symptom averages and the psychological symptoms such as obsessive-compulsive symptoms, depression, anxiety, anger hostility at 0.01 level ( $p>0.05$ ). According to the findings of the present research, symptoms, such as obsessive-compulsive symptoms, paranoid thoughts, interpersonal sensitivity and anger hostility are observed, and general symptom average was high among students of Faculty of Sports Sciences and psychological symptoms such as obsessive-compulsive symptoms, depression, anxiety, anger hostility, phobic reaction decreased as the physical activity level of the students increased. Psychological symptoms other than psychotics were mostly among female students. Participation in meditation, yoga, music therapy, exercise and physical activity programs as well as applied lessons in the curriculum can contribute to the prevention of mental problems among students with these symptoms.
\end{abstract}

Keywords: physical activity, psychological symptom, university student

\section{Introduction}

Time during university education is a critical period when university students spread an effort to gain identity and independence developmentally on one hand and struggle with the problem that come along with university life on the other (Rickwood et al., 2007). Studies conducted on university students' problem areas and needs have revealed that students face various psychological problems during university years and need help (Erkan et al., 2012). Especially those who have a chance to study at university face many problems such as separation from family, new environment and making friends, fear of being alone, economic difficulties and adaptation to dormitory life, future career and worry about working life besides the joy of getting into university (Özdel et al., 2002).

Youth is the period of contradictions in which the individuals experience many emotional, behavioral, sexual, economic, academic and social conflicts which result in social and physical changes and efforts to define an identity increase with sexual maturity. In this period the emotional health of university youth becomes one of the important components of social health (Kaya et al., 2007). For this reason identifying university students with the psychological symptoms is important. Even mild the psychological symptoms prompt the individuals to inactivity, inefficiency and unhappiness. For this reason reaching the individuals with psychological symptoms is important in terms of preventive mental health.

Psychological symptoms emerge during the difficult times of human life. In the face of various adverse environmental conditions, the individuals sometimes have difficulty and experience adjustment problems. Such problems affect the individual's vital activities and productivity. The psychological symptoms that produce these negative effects are related to the psychology and behavior that result from a general anxiety (Kerimova, 2000). In other words psychological 
symptoms are symptoms that affect mental health negatively and enable the diagnosis of mental illnesses (Kıliç, 1987). The psychological symptoms among individuals are as follows:

1. Somatization: It is stress related to various bodily functions. Somatization involves many somatic complaints which are not due to any physical impairment, last for many years and recur. It includes such symptoms as fainting, memory loss, chest pain, agoraphobia, loss of appetite, abdominal pain, nausea, shortness of breath, cold and hot flushes, numbness and tingling (Alver et al., 2010).

2. Obsessive-compulsive disorder: It includes recurring thoughts and behaviors that bother the individual and are unintentional, ego dystonic and cannot expelled by conscious effort (Alver et al., 2010).

3. Interpersonal sensitivity: Hypersensitivity includes symptoms such as believing that others produce bad ideas about themselves, perceiving themselves as inferior than others, and fear of failure (Alver et al., 2010).

4. Depression: It includes symptoms and behaviors such as grief, pessimism, discomfort, hopelessness, loneliness, unhappiness, distress, reluctance, negative feelings about self, suicidal tendency, loss of interest and indecision (Alver et al., 2010).

5. Anxiety disorder: A worrisome feeling that appears when it feels like a strong desire or impulse won't reach its goal (Alver et al., 2010).

6. Anger hostility: It includes symptoms such as irritability and tremor, anger, insecurity, desire to harm, beat and injure someone (Alver et al., 2010).

7. Phobic anxiety: It includes symptoms and behaviors such as agoraphobia (fear of open places), trying to avoid the feared objects or activities, fear of crowds, feeling nervous when alone (Alver et al., 2010).

8. Paranoid thoughts: The tendency to have extreme thoughts such as not trusting, skepticism, jealousy, blaming others (Alver et al., 2010).

9. Psychoticism: It is a case of estranging from the social circle and distinct schizophrenic delusions. It includes symptoms such as thinking that someone else can control their own thoughts, feeling lonely in the crowd and thinking that they should be punished for their sins (Alver et al., 2010).

Studies conducted on university students indicate that depression is the most threatening psychological disorder among university students. Depression which is defined as a syndrome that includes symptoms such as sorrow, sadness, reluctance, pessimism, worthlessness, inadequacy, weakness, decreased activity, inertness, slowing down of physiological functions, is one of the most discussed problems in the field of mental health in recent years (Özdel et al., 2002).

The positive effects of physical activity on physical and mental health are recognized (Lin et al., 2008). For this reason physical activity can be used as a tool to prevent psychological symptoms and to protect mental health among university students.

Physical activity is defined as body movements that occur with the contraction of skeletal muscles and increase energy expenditure above the basal level (McArdle et al., 2001). Physical activity improves physiological, metabolic and psychological parameters, reduces many chronic diseases and premature mortality and helps maintain bone, muscle and joint health (Heyward, 2006). Regular physical activity is known to have effects on mental health such as reducing depression and anxiety, regulating sleep, providing relief and increasing self-esteem (Adams et al., 2003). For this reason the purpose of the present research is determining students presenting psychological symptoms such as somatization, obsessive-compulsive disorder, interpersonal sensitivity, depression, anxiety, anger hostility, phobic anxiety, paranoid thoughts and psychoticism and studying the relationship between physical activity and psychological symptoms observed among students. Accordingly, the main purpose of the present research is revealing the importance of physical activity in terms of protecting the mental health among students of Faculty of Sport Sciences.

\section{Method}

\subsection{Participants}

The sample of the research consists of 222 volunteer students ( $n=75$ female and $n=147$ male) who study at Adnan Menderes University Faculty of Sports Sciences in 2017-2018 Academic Year.

\subsection{Data Collection Tools}

International Physical Activity Questionnaire (IPAQ) was used to define the physical activity levels of students and Symptom Distress Check List (SCL-90-R) was used to define the psychological symptoms of the students. 


\subsubsection{International Physical Activity Questionnaire}

The International Physical Activity Questionnaire (IPAQ) was developed in 1998 by and International Consensus Group appointed by World Health Organization in short and long forms. IPAQ was designed to define adult physical activity levels and inactivity states. Craig et al. (2003) who conducted a study to test the validity and reliability of IPAQ, reported that criterion validity of the questionnaire was 0.33 for the long form and 0.30 for the short form.

The validity and reliability studies of the questionnaire in Turkey was performed by Özturk (2005) who reported that the short and long forms of the questionnaire could provide repeatable and comparable data $(\mathrm{r}=0.66)$ and criterion validity of the questionnaire was $\mathrm{r}=0.30$ for the short form and $\mathrm{r}=0.29$ for the long form.

MET (Metabolic equivalent) values of individuals can be calculated from the data obtained from IPAQ. Frequency, duration and intensity variables are used to calculate MET values. Frequency refers to the number of days a week activity is performed duration refers to the length of time (in hours or minutes) the activity is performed each time and intensity refers the amount of MET spent per hour during the activity. MET is a measure of the rate of oxygen consumed per kilogram unit. A MET corresponds to the amount of oxygen consumed during rest (about $3.5 \mathrm{ml} / \mathrm{kg} / \mathrm{min}$ ) (Craig et al., 2003). The following formula is used to calculate the MET min/week values:

MET / week: Frequency of activity X Duration of activity X Intensity of activity (Karaca \& Turnagöl 2007).

\subsubsection{Symtom Distress Checklist SCL-90-R}

The Symptom Distress Checklist was developed at the Psychometrics Research Unit of the John Hopkins University by Leonard R. Derogatis et al. (1971, 1973, 1974, 1976, 1977) using the inventory known as Hopkins Symptom Check List (HSCL). The Symptom Distress Checklist SCL-90-R is a tool that defines the levels of psychological symptoms observed among individuals and the areas they are spread.

Four new dimensions Anger-hostility (HOS), Phobic reaction (PHOB), Paranoid thought (PAR), Psychotics (PSY) were added to five symptom dimensions of HSCL. Somatization (SOM), Obsessive-compulsive (O-C), Interpersonal sensitivity (INT), Depression (DEP), Anxiety (ANX) and it became a self-report inventory marked as 0-1-2-3-4 between levels of "Not at all" and "Extremely" consisting of 9 sub-items in 10 symptom groups (9 sub and 1 additional scale) (Kılıç, 1987).

The norm determination study of the inventory was conducted on a heterogeneous sample of 1.000 psychiatric patients in the United States (Derogatis et al., 1976). The internal structure reliability coefficients defined by Deragotis et al. (1976) in the reliability study of SCL-90-R are as follows: Somatization (SOM) 0.86, Obsessive-compulsive (O-C) 0.86 , Interpersonal sensitivity (INT) 0.86, Depression (DEP) 0.90, Anxiety (ANX) 0.85, Anger-hostility (HOS) 0.84, Phobic anxiety (PHOB) 0.82, Paranoid thought (PAR) 0.80, Psychotics (PSY) 0.77.

Symptom Check List SCL-90-R was first used in Turkey by Gökler (1978). Birsöz (1980) applied it on inpatients and outpatients of Hacettepe University Hospitals Psychiatric Clinics with various diagnoses in order to test whether the tool was comprehensible enough and reported that the patients did not have any difficulties in understanding and responding to the items and communicated easily with the tool.

\subsection{Statistics and Data Analysis}

The data collected to determine the physical activity levels and the psychological symptoms observed among the students participating in the present research were evaluated in the SPSS 22.0 package program. Normality of the distribution of the data was tested with Kolmogorov-Smirnov Test. Independent Sample T Test was used to compare two independent variables as the data presented normal distribution. Whether there was a linear relationship between the two variables and if there was the level and direction of the relationship was tested with Pearson correlation coefficient ( $\mathrm{r}$ ).

\section{Findings}

Table 1. Descriptive Statistics on Students

\begin{tabular}{lcccc}
\hline \multirow{2}{*}{ Grade } & \multicolumn{2}{c}{ Gender } & \multicolumn{2}{c}{ Male } \\
\cline { 2 - 5 } & $\boldsymbol{N}$ & $\mathbf{\%}$ & $\boldsymbol{N}$ & $\mathbf{\%}$ \\
\cline { 2 - 5 } & 22 & 29.3 & 50 & 34.0 \\
\hline $\mathbf{1}^{\text {st }}$ grade & 25 & 33.3 & 35 & 23.8 \\
$\mathbf{2}^{\text {nd }}$ grade & 13 & 17.3 & 26 & 17.7 \\
$\mathbf{3}^{\text {rd }}$ grade & 15 & 20.0 & 36 & 24.5 \\
$\mathbf{4}^{\text {th }}$ grade & $\mathbf{7 5}$ & $\mathbf{1 0 0}$ & $\mathbf{1 4 7}$ & $\mathbf{1 0 0}$ \\
\hline Total & & & \\
\hline
\end{tabular}

Table 1. shows descriptive statistics on the gender and class levels of the students participating in the research. 
Table 2. Psychological Symptoms Observed Among Students

\begin{tabular}{lcccccc}
\hline \multirow{2}{*}{ Psychological Symptoms } & \multicolumn{9}{c}{ Mental Status } \\
\cline { 2 - 7 } & \multicolumn{2}{c}{ No Problems } & \multicolumn{3}{c}{ Mild } & \multicolumn{2}{c}{ Existing } \\
\cline { 2 - 7 } & $\boldsymbol{N}$ & $\boldsymbol{\%}$ & $\boldsymbol{N}$ & $\mathbf{\%}$ & $\boldsymbol{N}$ & $\boldsymbol{\%}$ \\
\hline Somatization & 43 & 19.4 & 77 & 34.7 & 102 & 45.9 \\
Obsessive compulsive symptoms & 20 & 9 & 46 & 20.7 & 156 & 70.3 \\
Interpersonal sensitivity & 39 & 17.6 & 68 & 30.6 & 115 & 51.8 \\
Depression & 46 & 20.7 & 77 & 34.7 & 99 & 44.6 \\
Anxiety & 71 & 32 & 70 & 31.5 & 81 & 36.5 \\
Anger - hostility & 66 & 29.7 & 42 & 18.9 & 114 & 51.4 \\
Phobic reaction & 120 & 54.1 & 65 & 29.3 & 37 & 16.7 \\
Paranoid thoughts & 34 & 15.3 & 48 & 21.6 & 140 & 63.1 \\
Psychoticism & 96 & 43.2 & 67 & 30.2 & 59 & 26.6 \\
General symptom average & 34 & 15.3 & 74 & 33.3 & 114 & 51.4 \\
\hline
\end{tabular}

The frequency distributions of the psychological statements observed among the students participating in the research are presented in Table 2.

Table 3. The Relationship between Students' Level of Physical Activity and the Psychological Symptoms

\begin{tabular}{|c|c|c|c|c|c|c|c|c|c|c|c|}
\hline & MET & SOM & O-C & INT & DEP & ANX & HOS & PHOB & PAR & PSY & GSO \\
\hline MET & 1.000 & & & & & & & & & & \\
\hline SOM & -0.121 & 1.000 & & & & & & & & & \\
\hline O-C & $-0.213 * *$ & $0.600 * *$ & 1.000 & & & & & & & & \\
\hline INT & -0.888 & $0.507 * *$ & $0.668 * *$ & 1.000 & & & & & & & \\
\hline DEP & $-0.225 * *$ & $0.620 * *$ & $0.714 * *$ & $0.722 * *$ & 1.000 & & & & & & \\
\hline $\mathbf{A N X}$ & $-0.245 * *$ & $0.700 * *$ & $0.687 * *$ & $0.630 * *$ & $0.738 * *$ & 1.000 & & & & & \\
\hline HOS & $-0.238 * *$ & $0.551 * *$ & $0.602 * *$ & $0.607 * *$ & $0.615^{* *}$ & $0.688 *$ & 1.000 & & & & \\
\hline PHOB & $-0.149 *$ & $0.501 * *$ & $0.529 * *$ & $0.561 * *$ & $0.587 * *$ & $0.687 * *$ & $0.551 * *$ & 1.000 & & & \\
\hline PAR & -0.103 & $0.495 * *$ & $0.580 * *$ & $0.634 * *$ & $0.605 * *$ & $0.636 * *$ & $0.547 * *$ & $0.522 * *$ & 1.000 & & \\
\hline PSY & -0.097 & $0.566^{* *}$ & $0.601 * *$ & $0.663 * *$ & $0.713 * *$ & $0.731 * *$ & $0.566 * *$ & $0.678 * *$ & $0.640 * *$ & 1.000 & \\
\hline GSA & $-0.202 * *$ & $0.777 * *$ & $0.829 * *$ & $0.809 * *$ & $0.885^{* *}$ & $0.891 * *$ & $0.767 * *$ & $0.736^{* *}$ & $0.741 * *$ & 0.834 & 1.000 \\
\hline
\end{tabular}

* Significant at 0.05 level (2 way); ** Significant at 0.01 level (2 way); MET: Metabolic equivalent; SOM: Somatization; O-C: Obsessive-compulsive symptoms; INT: Interpersonal sensitivity; DEP: Depression; ANX: Anxiety; HOS: Anger-hostility; PHOB: Phobic reaction; PAR: Paranoid thought; PSY: Psychoticism; GSA: General symptom average

According to correlation coefficients presented in Table 3, there is a significant negative correlation at 0.01 level between psychological symptoms observed among participants such as obsessive-compulsive symptoms, depression, anxiety, anger hostility and general symptom averages and their physical activity levels. Additionally, there is a significant negative correlation at 0.05 levels between physical activity levels of students and phobic reaction. On the other hand, there is no significant relationship between physical activity levels and somatization, interpersonal sensitivity, paranoid thoughts and psychotics.

\section{Discussion and Conclusion}

In addition to its physical and physiological benefits, exercise is known to reduce stress, to provide psychological wellbeing to increase life satisfaction and to be among the treatment methods of psychiatric rehabilitation programs (Soyer et al., 2017). Regular physical activity is an important activity that helps individuals feel good and reduces symptoms of depression (Isik et al., 2014). The present research which aims to determine the psychological symptoms among the students of the Faculty of Sports Sciences and to determine the effects of physical activity on protecting the mental health of the students found that psychological problems are observed among many of the participants. The most common psychological symptoms observed among the students who participated in the present research respectively were obsessive-compulsive symptoms in 70.3\% ( $\mathrm{n}=156)$, paranoid thoughts in $63.1 \%(\mathrm{n}=140)$, interpersonal sensitivity in $51.8 \%(\mathrm{n}=115)$ and anger-hostility in $51.4 \%(\mathrm{n}=115)$. It was found that all psychological symptoms other than psychotic were more common among female students. There was a significant negative correlation at 0.01 levels between psychological symptoms such as obsessive-compulsive symptoms, depression, anxiety, anger hostility, phobic reaction and general symptom averages and physical activity levels of the participants of the present research. Accordingly as physical activity levels increase, psychological symptoms and general symptom averages of students decrease. Similar studies have reported that regular exercise protects young people from major illnesses such as cardiac diseases, blood pressure, obesity and type 2 diabetes, and that lower depression levels among young people and adults (Dehghan et al., 2005; Penedo \& Dahn 2005; Paluska \& Schwenk 2000; Prasad et al., 2009; Tyson et al., 2010). Physical and mental problems found to decrease after a program including thinking, emotional development, exercise and nutrition education organized for overweight young people with depression and anxiety disorders (Melnyk et al., 
2009). Archer et al. (2014) reported that physical activity and exercise contributed to mental development and reducing stress. In their studies reporting that as the level of physical activity decreased the risk for depression increased. Azar et al. (2011) found a negative relationship between physical activity and depression risk. Sund et al. (2011) reported that physical activity was an important indicator of depressive symptoms. Suh et al. (2012) reported that physical activity programs and social support resulted in decrease in depressive symptoms.

In the research on the relationship between the level of physical activity, psychological symptoms and quality of life among students staying in orphanages, aged 13-16 Karadağ (2008) reported that students who are engaged in sports had lower smoking, alcohol, substance and drug use frequency, higher quality of life scores, lower general mental symptom and depression scores, lower desire to hurt and damage, and higher frequency of studying and reading. It was also found that as the duration of time allocated to sports increased, psychological symptoms decreased, life quality scores, time spent with friends, and the sense of success among friends increased among adolescents.

According to the findings of the present research especially symptoms such as obsessive-compulsive symptoms, paranoid thoughts, interpersonal sensitivity and anger hostility are observed among the students of the Faculty of Sports Sciences and their general symptom averages are high and obsessive-compulsive symptoms, depression, anxiety, anger hostility, phobic reaction and general symptom average decrease as the physical activity level of the students increases. For this reason students with these symptoms can participate in meditation, yoga, music therapy, exercise and physical activity programs, as well as applied lessons in the curriculum. While organizing these programs, indicators of physical activity, such as frequency, duration, type and intensity should be taken into consideration. In order to prevent the psychological symptoms observed among the students, they should be given aerobic activities, muscle strengthening activities and balance activities at least 3 times a week, no less than 30 minutes.

\section{References}

Adams, J. M., Miller, T. W., \& Kraus, R. F. (2003). Exercise dependence: Diagnostic and therapeutic issues for patients in psychotherapy. J Contemp Psychother, 33(2), 93-107. https://doi.org/10.1023/A:1022883104269

Alver, B., Dilekmen, M., \& Ada, Ş. (2016). Psychological symptoms of university students regarding their subjective perceptions. Turkish Psychological Counseling and Guidance Journal, 4(33), 13-23.

Archer, T., Josefsson, T., \& Lindwall, M. (2014). Effects of physical exercise on depressive symptoms and biomarkers in depression. CNS \& Neurological Disorders-Drug Targets (Formerly Current Drug Targets-CNS \& Neurological Disorders), 13(10), 1640-1653.

Azar, D., Ball, K., Salmon, J., \& Cleland, V. (2011). Individual, social, and physical environmental correlates of physical activity among young women at risk of depression. Journal of Physical Activity and Health, 8(1), 133-140. https://doi.org/10.1123/jpah.8.1.133

Birsöz, S. (1980). A review of pre-disease life changes and psychological consequences. Hacettepe University Unpublished doctoral dissertation, Ankara.

Craig, C. L., Marshall, A. L., Sjorstrom, M., Bauman, A. E., Booth, M. L., Ainsworth, B. E., ... \& Oja, P. (2003). International physical activity questionnaire: 12-country reliability and validity. Medicine and Science in Sports and Exercise, 35(8), 1381-1395. https://doi.org/10.1249/01.MSS.0000078924.61453.FB

Dehghan, M., Akhtar-Danesh, N., \& Merchant, A. T. (2005). Childhood obesity, prevalence and prevention. Nutrition Journal, 4, 24-32. https://doi.org/10.1186/1475-2891-4-24

Derogatis, L. R., Rickels, K., \& Rock, A. F. (1976). The SCL-90 and the MMPI: A step in the validation of a new self-report scale. The British Journal of Psychiatry, 128(3), 280-289. https://doi.org/10.1192/bjp.128.3.280

Erkan, S., Özbay, Y., Çankaya, Z. C., \& Terzi, Ş. (2012). University students' problem areas and psychological help-seeking willingness. Education and Science, 37(164), 94-107.

Gökler, B. (1978). Assessment of neurotic female patients in terms of psychological symptoms of primary school children. Hacettepe University Department of Psychiatry, Unpublished speciality dissertation, Ankara.

Heyward, V. H. (2006). Advanced Fitness Assessment and Exercise Prescription. 5th ed. USA: Human Kinetics.

Isik, O., Gumus, H., Okudan, B., \& Yilmaz, M. (2014). Evaluation of the effects of the quality of life levels of university students upon their depression levels. International Journal of Science Culture and Sport, 2(5), 836-843. http://dx.doi.org/10.14486/IJSCS157

Karaca, A., \& Turnagöl, H. H. (2007). Reliability and validity of three different questionnaires in employees. Hacettepe Journal of Sport Sciences, 18(2), 68-84.

Karadağ, Ö. (2008). Assessment of mental symptoms and quality of life in association with sociodemographic 
characteristics and physical activity levels of adolescents living in orphanages in Ankara. Hacettepe University, Institute of Health Science, Unpublished master dissertation, Ankara.

Kaya, M., Genç, M., Kaya, B., \& Pehlivan, E. (2007). Prevalence of depressive symptoms, ways of coping, and related factors among medical school and health services higher education students. Turkish Journal of Psychiatry, 18(1), 137-146.

Kerimova, M. (2000). Examination of psychological symptoms seen in high school students according to some variables. Hacettepe University, Institute of Social Science, Unpublished master dissertation, Ankara.

Kılıç, M. (1987). Problems of students with and without various psychological disorders. Hacettepe University, Institute of Social Science, Unpublished doctorate dissertation, Ankara.

Lin, L., Halgin, R. P., Well, A. D., \& Ockene, I. (2008). The relationship between depression and occupational, household, and leisure-time physical activity. Journal of Clinical Sport Psychology, 2(2), 95-107.

McArdle, W. D., Katch, F. I., \& Katch, V. L. (2001). Energy expenditure in household, occupational, recreational, and sports activities. Exercise Physiology: Energy, Nutrition and Human Performance, 769-781.

Melnyk, B. M., Jacobson, D., Kelly, S., O'Haver, J., Small, L., \& Mays, M. Z. (2009). Improving the mental health, healthy lifestyle choices, and physical health of Hispanic adolescents: A randomized controlled pilot study. Journal of School Health, 79(12), 575-584. https://doi.org/10.1111/j.1746-1561.2009.00451.x

Özdel, L., Bostanc1, M., Özdel, O., \& Oğuzhanoğlu, N. K. (2002). The relationship with sociodemographic characteristics and depressive symptoms in university students. Anatolian Journal of Psychiatry, 3(3), 155-161.

Öztürk, M. (2005). A research on reliability and validity of international physical activity questionnaire and determination of physical activity level in university students. Hacettepe University, Institute of Health Science, Unpublished master dissertation, Ankara.

Paluska, S. A., \& Schwenk, T. L. (2000). Physical activity and mental health. Sports Medicine, 29(3), 167-180. https://doi.org/10.2165/00007256-200029030-00003

Penedo, F.J., \& Dahn, J.R. (2005). Exercise and well-being: A review of mental and physical health benefits associated with physical activity. Current Opinion in Psychiatry, 18(2), 189-193.

Prasad, A., St-Hilaire, S., Wong, M. M., Peterson, T., \& Loftin, J. (2009). Physical activity and depressive symptoms in rural adolescents. North American Journal of Psychology, 11(1), 173-187.

Rickwood, D. J., Deane, F. P., \& Wilson, C. J. (2007). When and how do young people seek professional help for mental health problems?. Medical Journal of Australia, 187(7), 35-39.

Soyer, F., Yıldız, N. O., Demirel, D. H., Serdar, E., Demirel, M., Ayhan, C., \& Demirhan, O. (2017). The investigation of the relationship between the factors that prevent university students from attending to the recreational activities and the life satisfaction of the participants. Journal of Human Sciences, 14(2), 2035-2046. https://www.doi.org/10.14687/jhs.v14i2.4647

Suh, Y., Weikert, M., Dlugonski, D., Sandroff, B., \& Motl, R. W. (2012). Physical activity, social support, and depression: Possible independent and indirect associations in persons with multiple sclerosis. Psychology, Health \& Medicine, 17(2), 196-206. https://doi.org/10.1080/13548506.2011.601747

Sund, A.M., Larsson, B., \& Wichstrøm, L. (2011). Role of physical and sedentary activities in the development of depressive symptoms in early adolescence. Social Psychiatry and Psychiatric Epidemiology, 46 (5), 431-441.

Tyson, P., Wilson, K., Crone, D., Brailsford, R., \& Laws, K. (2010). Physical activity and mental health in a student population. Journal of Mental Health, 19 (6), 492-499.

\section{Copyrights}

Copyright for this article is retained by the author(s), with first publication rights granted to the journal.

This is an open-access article distributed under the terms and conditions of the Creative Commons Attribution license which permits unrestricted use, distribution, and reproduction in any medium, provided the original work is properly cited. 